ISSN 25980580

Bioscientia Medicina Volume 4, Issue 1, Page No: 19-28

Available online : www.bioscmed.com

Bio Sc Med 4(1):19-28

\title{
Papaya (Carica Papaya L.) Seed Extract as Male Contraception via Decreasing The Quality of Rat's (Rattus Norvegicus) Sperm
}

\author{
Sri Nita ${ }^{1 \#}$, Arum Setiawan ${ }^{2}$, Rara Inggarsih ${ }^{1}$, Uci Tantri ${ }^{1}$, Meryska Herdiana ${ }^{1}$ \\ ${ }^{1}$ Department of Biology, Faculty of Medicine, Universitas Sriwijaya, Indonesia \\ ${ }^{2}$ Department of Biology, Faculty of Science and Mathematics, Universitas Sriwijaya, Indonesia \\ \#Correspondence Author E-mail : srinita1970@gmail.com
}

Received : October $23^{\text {rd }} 2019$

Accepted : December $25^{\text {th }} 2019$

\begin{abstract}
Background. Population growth needs to be controlled so as not to cause new and serious problems. Pregnancy and birth control is a solution to control this sizable population growth. Contraception is a way to prevent pregnancy, by inhibiting the process of ovulation, fertilization and implantation. Nevertheless, most of contraceptive regiments were aimed to woman. Male contraception nowadays is very rare. Papaya seed is one of the male contraceptive candidates which has the potential to be developed as male contraception. Previous studies have shown the potential of papaya seed extract could reduce the weight of reproductive organs of male white rats, where it was believed that there was a decrease in spermatogenesis activity.

Methods. This research was an in-vivo experimental research post-test only with control group. The study used 32 male and healthy rats (Rattus norvegicus) Wistar strain with 8-10 weeks of age. Rats were grouped into 1 control group and 4 treatment groups that were randomly selected. The four treatment groups were group 1: control administered $1 \% 2 \mathrm{ml} \mathrm{CMC}$ orally one time per day every morning, group 2: were given $\mathrm{N}$-hexane papaya seed fraction, group 3: were given ethyl acetate papaya seed fraction and group 4: were given ethanol-water papaya seed fraction. The three fractions were given to rats orally at a dose of $100 \mathrm{mg} / \mathrm{KgBB} /$ day for 24 days. After that, rat's testes and epidydimis were evacuated to observe reproductive organs and sperm quality.

Results. Anatomically, Group 2 and 3 were statistically significant in reducing testicular's and epidydimis' weight compared to the control group, but the n-hexane group was more effective in reducing testicular weight than other treatment groups. Furthermore, groups 2,3 and 4 were statistically significant in reducing sperm quality (motility, viability, amount of sperm cells and normal sperm cell morphology) compared to the control group, but the $\mathrm{n}$ hexane group was more effective in reducing sperm quality than other treatment groups.

Conclusion. Papaya seed $\mathrm{n}$-hexane fraction has potential as a male contraceptive by reducing spermatogenesis activity and decreasing sperm quality in white rats.
\end{abstract}

Keywords : papaya seed, male contraception, rat's sperm

\section{Introduction}

Indonesia is the fourth most populous country in the world with a population of 270 million. The huge potential of human resources makes Indonesia as a country with potent economic power that will be able to grow very large if it is able to be managed properly. While on the other hand, this very large and rapid population growth will be a serious problem because it will require natural resources and management of education, health and large employment 
ISSN 25980580

management. This population growth needs to be controlled so as not to cause new and serious problems, in the form of food and natural resource crises. Pregnancy and birth control is a solution to control this sizable population growth. Contraception is one way to prevent pregnancy, by inhibiting the process of ovulation, fertilization and implantation. ${ }^{1}$

Male participation in contraception was much lower than in women $(6.34 \%$ vs. 93.66\%). More contraception is aimed at women, while in men it is still very limited. New problems have arisen, due to hormonal, estrogen and progesterone-based female contraceptives, which adversely affect health, due to triggering various degenerative diseases and malignancies. Exploration of contraception for men is an optimal strategy to control pregnancy and birth. ${ }^{2-3}$ The use of natural materials is one of the efforts to explore new male contraceptive modalities, bearing in mind that Indonesia is rich in natural potential in the form of plants with the second largest drug potential in the world. ${ }^{4}$

Papaya seed is one of the male contraceptive candidates which has the potential to be developed as contraception. Previous studies have shown the potential of papaya seed extract at a dose of $100 \mathrm{mg} / \mathrm{kgBB}$ capable of reducing the weight of reproductive organs of white rats, where it is believed that there is a decrease in spermatogenesis activity that will reduce the weight of reproductive organs, testicles, white rats. ${ }^{5-8}$ The content of secondary metabolites from seeds Papaya is believed to play a role in the potential for contraception. Alkaloids are one of the secondary metabolites that are believed to play a large role in the effects of antifertility. Alkaloids are cytotoxic so they inhibit the development of leydig cells in producing testosterone. In addition to the alkaloids, triterpenoids and steroids contained in papaya seeds that affect the testosterone levels by inhibiting feedback mechanisms in the hypothalamic pituitary to reduce the production of LH (Luteinizing Hormone) and FSH (Follicle Stimulating Hormone).

This research was the first research that would explore further from papaya seed extract. Where papaya extract would be processed via fractionation in order to separate dissolved compounds based on polarity level. Furthermore, the potential test of papaya seeds as antifertility agent would be carried out by looking at the sperm quality of white rats. 


\section{Methods}

This research was an in-vivo experimental research post-test only with control group. The study used 32 white rats (Rattus norvegicus) Wistar strain with 8-10 weeks of age, males, body weight 150-200 grams and healthy rats. Rats were obtained from Eureka Research Laboratory (ISO 9001: 2015). Rats were given regular food and drink ad libitum.

Rats were grouped into 1 control group and 4 treatment groups that were randomly selected. Each group consisted of 8 rats. The four treatment groups were group 1: control administered $1 \% 2 \mathrm{ml} \mathrm{CMC}$ orally one time per day every morning, group 2: were given $\mathrm{N}$ hexane fraction, group 3: were given ethyl acetate fraction and group 4: were given ethanolwater fraction. The three fractions were given to rats orally at a dose of $100 \mathrm{mg} / \mathrm{KgBB} / \mathrm{day}$. Each rat was put into individual cages according to the group 24-day treatment duration. On the 25th day after treatment, rats were euthanized and the testes and epididymis were evacuated. Then the organs are cleaned in $0.9 \% \mathrm{NaCl}$ solution after that the organs were weighed. The left epididymis and testicles are set aside and immersed in $4 \%$ formalin fixative solution for histological preparations. Whereas the right epididymis was taken for the preparation and observation of spermatozoa quality.

\section{Papaya Seed Extraction and Fractionation}

Papaya seeds (Carica papaya) were obtained from the Center for Research and Development of Medicinal Plants Tawangmangu, Indonesia. Papaya seeds were dried first, then they were crushed the seeds into powder. Furthermore, the simplicia powder was soaked with $96 \%$ ethanol by maceration method for 72 hours. Next, maserat was carried out in a gradually liquid-liquid fractionation with ethylacetate and n-hexane to obtain ethyacetate, nhexane and ethanol-water fractions.

\section{Testis and Tubulus Seminiferous Histology}

Each testis of a rat was made to one histology preparation. Observation of testicular histology was using a microscope with 100x and 400x magnification. Measurement of the diameter of the seminiferous tubules was using a micrometerocular. To count tubulus seminiferous, 5 tubulus seminiferous were taken with 400 times-magnification. 


\section{Epididymis Histology}

Each epididymis from rat was made one histology preparations. Observation of epididymal histology was using a microscope with a magnification of 400 times. Measuring the thickness of the epididymal epithelium was using an ocular micrometer.

$$
\text { Epididymis Epithelial Thickness }=\frac{\text { Epididymis Diameter }- \text { Epididymis Lumen Diameter }}{2}
$$

\section{Sperm Motility}

Sperm motility was measured by looking at the speed of sperm in the neubauer counting chamber. One drop of sperm suspension in $0.9 \% \mathrm{NaCl}$ solution was dripped in a counting chamber then observed under a 400-magnification microscope. Observations were made on 200 sperms, then repeated 3 times for one mouse and the results were averaged. Sperm motility is expressed in percent units. The percentage of the number of motile sperms is determined by adding up the PR (Progressive motility) + NP (non-progressive) categories, divided by the number of PR + NP + IM (immotility) categories and then multiplying by $100 \%$.

\section{Sperm Viability}

To observe the viability of sperm, an Eosin Y $10 \mu$ ldye was dripped on the object glass then sperm was added from the preparation, covered with a covering glass. Observation of spermatozoa viability was performed on 200 spermatozoa cells under a light microscope with 400x magnification. Observations viewed under a microscope, living spermatozoa would not be colored by Eosin Y but spermatozoa that have died would be turn into purplish red colour due to damage to the plasma membrane of spermatozoa cells. Determination of spermatozoa viability expressed in percent $100 \%$.

$$
\text { Spermatozoa Viability Percentage }=\frac{\text { Amount of Alive Spermatozoa }}{\text { Total Spermatozoa (alive and dead) }} \times 100 \%
$$

\section{Spermatozoon Counting}

Spermatozoa were counted using an Improved Neubaeur (hemocytometer) counting chamber. Amount 1-2 drops of sperm suspension from spermatozoa preparations was taken 
ISSN 25980580

with a pipette, and then it was placed in a hemocytometer. Next, it was covered with a glass cover. After that, it was calculated with a magnification of 400 times using a light microscope. In the counting chamber, hemocytometer was given borderline on all sides with a triple line. Only sperm whose head located on the upper line or left line of the plot would be count on. The sperm count would be expressed in unit number (million) / spermatozoa concentration (ml)

\section{Spermatozoon Morphology}

Spermatozoon morphology was observed from smears made on clean glass slide by dripping one drop of sperm suspension. Then the suspension was flattened with the help of another slide, the sperm smear was dried by itself. After drying, the preparation was fixed with $40 \%$ methanol for 5 minutes. The slide then was rinsed with distilled water and dried. Then the slide is dropped with $3 \%$ Giemsa dye and left for 30 minutes, then rinsed again with tap water and dried at room temperature. Observations were made under a 400-magnification microscope of 200 sperm in each treatment group, the results expressed in percent.

\section{Data Analysis}

Data analysis was performed using SPSS 24 software. Data analysis was carried out bivariately with ANOVA test and multivariate test was carried out with the post hoc test, Duncan test, to see the differences of each treatment group. Probability, $\mathrm{p}<0.05$.

\section{Results}

This study revealed that there were differences in macroanatomic of reproductive organs between control group and treatment groups. Table 1 shows comparison macroanatomic structures among groups in this study. 
Table 1. Macroanatomic Comparison of Reproductive Organs Among Groups

\begin{tabular}{ccccc}
\hline Group & $\begin{array}{c}\text { Testis Weight } \\
(\mathbf{g})\end{array}$ & $\begin{array}{c}\text { Epydidimis Weight } \\
(\mathbf{g})\end{array}$ & $\begin{array}{c}\text { Seminiferous Tubules } \\
\text { Diameter }(\mathbf{u m})\end{array}$ & $\begin{array}{c}\text { Epithelium of Seminiferous } \\
\text { Tubules Thickness(um) }\end{array}$ \\
& Mean \pm SD & Mean \pm SD & Mean \pm SD & Mean \pm SD \\
\hline $\mathbf{1}$ & $1,52 \pm 0,63$ & $0,43 \pm 0,02$ & $331,59 \pm 130,26$ & $27,58 \pm 13,21$ \\
$\mathbf{2}$ & $1,36 \pm 0,17^{*}$ & $0,38 \pm 0,03^{*}$ & $217,11 \pm 51,90^{*}$ & $10,72 \pm 7,62^{*}$ \\
$\mathbf{3}$ & $1,47 \pm 0,06^{*}$ & $0,40 \pm 0,02^{*}$ & $219,50 \pm 50,24^{*}$ & $16,72 \pm 7,30^{*}$ \\
$\mathbf{4}$ & $1,52 \pm 0,05$ & $0,41 \pm 0,02^{*}$ & $302,68 \pm 62,29^{*}$ & $20,28 \pm 8,30^{*}$ \\
\hline
\end{tabular}

$* \mathrm{p}<0,05$; poshoc Duncan test VS Group 1

Group 2 and 3 were statistically significant in reducing testicular weight compared to the control group, but the $n$-hexane group was more effective in reducing testicular weight than other treatment groups. Groups 2, 3 and 4 were statistically significant in reducing the weight of epididymis compared to the control group, but the n-hexane fraction was able to reduce the weight of epididymis more effectively than the other treatment groups. Groups 2, 3 and 4 were statistically significant in reducing the diameter of the seminiferous tubules compared to the control group, but the n-hexane fraction was able to reduce the diameter of the seminiferous tubules more effectively than the other treatment groups. Groups 2, 3 and 4 were statistically significant in reducing the thickness of the seminiferous tubule epithelium compared to the control group, but the n-hexane fraction was able to reduce the thickness of the seminiferous tubular epithelium more effectively than the other treatment groups.

Furthermore, table 2 shows comparison of sperm quality between group treatments and control group. Components of sperm quality were consisted of sperm motility, viability, amount of spermatozoa and normal spermatozoa morphology. 
ISSN 25980580

Table 2. Comparison of Sperm Quality Among Groups

\begin{tabular}{ccccc}
\hline Group & $\begin{array}{c}\text { Sperm } \\
\text { Motility }(\%)\end{array}$ & $\begin{array}{c}\text { Sperm Viability (\%) } \\
\text { Mean } \pm \text { SD }\end{array}$ & $\begin{array}{c}\text { Amount of Spermatozoa } \\
(\mathbf{m i l l i o n} / \mathbf{m L})\end{array}$ & $\begin{array}{c}\text { Normal Spermatozoa } \\
\text { Morphology (Unit) }\end{array}$ \\
\hline $\mathbf{1}$ & $71,04 \pm 9,33$ & $71,96 \pm 9,60$ & Mean \pm SD & Mean \pm SD \\
$\mathbf{2}$ & $51,91 \pm 8,46^{*}$ & $45,83 \pm 11,85^{*}$ & $199,193 \pm 15,79^{*}$ & $93,83 \pm 1,94$ \\
$\mathbf{3}$ & $52,04 \pm 12,87^{*}$ & $50,66 \pm 10,25^{*}$ & $222,081 \pm 56,79^{*}$ & $88,00 \pm 4,60$ \\
$\mathbf{4}$ & $66,16 \pm 3,62^{*}$ & $63,30 \pm 18,22^{*}$ & $261,305 \pm 28,50^{*}$ & $88,33 \pm 4,41$ \\
\hline${ }^{*} \mathrm{p}<0,05 ;$ poshoc Duncan test VS Group 1 & & $92,00 \pm 2,09$ \\
\hline
\end{tabular}

Groups 2, 3 and 4 were statistically significant in reducing sperm motility compared to the control group, but the n-hexane group was more effective in reducing sperm motility than other treatment groups. Groups 2, 3 and 4 were statistically significant in decreasing sperm viability compared to the control group, but the n-hexane fraction was able to reduce sperm viability more effectively than other treatment groups. Groups 2, 3 and 4 were statistically significant in lowering quantity of spermatozoa compared to the control group, but the nhexane fraction was able to reduce the number of spermatozoa more effective than other treatment groups. Group 2, 3 and 4 were statistically significant in reducing the normal morphology of the spermatozoa compared to the control group, but the n-hexane fraction was able to decrease the normal morphology of the spermatozoa more effectively than the other treatment groups.

\section{Discussion}

This study shows the potential of the n-hexane fraction of papaya seeds as male contraception at a dose of $100 \mathrm{mg} / \mathrm{kgBW}$. The $\mathrm{n}$-hexane fraction can reduce the weight of various reproductive organs (testes, epydidymis and seminiferous tubules) more effectively than other treatment groups. The decrease in weight of various reproductive organs is caused by a reduction in the activity of Leydig cells and Sertoli cells that will lead to decrease spermatogenesis activity and sperm performance. Decreased sperm performance can be seen in reduced motility, viability, sperm count and decreased normal morphology of sperm due to administration of the n-hexane fraction from papaya seeds. 
ISSN 25980580

Triterpenoids and steroids contained in papaya seeds affect the testosterone levels by inhibiting feedback mechanisms in the pituitary-hypothalamus to reduce the production of LH (Luteinizing Hormone) and FSH (Follicle Stimulating Hormone). LH and FSH from anterior pituitary gland play an important role in regulating the biological processes of reproduction in male animals, FSH stimulates the process of spermatogenesis and LH, often called ICSH (Interstitial Cell Stimulating Hormone), stimulates the growth and metabolism of leydig cells, to produce testosterone hormones. Sperm count and testosterone levels are held constant by feedback mechanisms. If the feedback mechanism is disrupted, the levels of FSH and LH in the blood circulation can decrease, as a result the process of spermatogenesis is stopped and the number of spermatozoa produced decreases in the seminiferous tubules. ${ }^{13-17}$

Severe decrease in epididymis weight was expected having relation to development disruption and disfunction of the epididymis. The epididymis consists of three regions, namely caput, corpus and cauda epididymis. The cauda region has the widest ductus diameter and lumen diameter. This is because the cauda area is the largest storage site for spermatozoa in the epididymis. About $75 \%$ of the total number of spermatozoa in the epididymis is in the cauda area. In addition, epididymis is a place for spermatozoa maturation. Epididymis has an important function in the maturation, storage and transportation of spermatozoa. Spermatozoa from the testes cannot be used to fertilize eggs in vivo. Proteins that are synthesized and secreted by epididymal epithelium play an important role in spermatozoa maturation. The decrease in weight of the epididymis is probably due to the n-hexane fraction of papaya seeds which have flavonoid compounds can cause damage to the epididymal cell membrane so that it can also cause the testosterone hormone which plays a role in maintaining the survival of spermatozoa in the epididymis also disturbed. ${ }^{18-19}$

\section{Conclusion}

Papaya seed $n$-hexane fraction has potential as a male contraceptive by reducing spermatogenesis activity and decreasing sperm quality in white rats.

\section{References}

1. BKKBN. Peningkatan Partisipasi Pria dalam KB \& KR. BKKBN. Jakarta; 2014.

2. World Health Organization. Traditional Medicine. Fact sheet No 134. Geneva; 2003. 
3. Msfhana NR, Abbiw DK, Addea-Mensah E, Ahiyi MRA, Ekpera JA, Enow-Drock EG, et al. Traditional medicine and pharmacopoeia. Contribution to the revision of ethnobotanical and floristic studies in Ghana. Organization of African Unity/Scientific, technical and research committee; 2000.

4. Udoh FV, Udoh PB, Umoh EE. Activity of alkaloid extract of Carica papaya. Seeds on reproductive functions in male wistar rats. Pharm Biol 2005;43:563-7.

5. Chinoy NJ. Structure and physiology of mammalian vas deferens in relation to fertility regulation. J Biol Sci 1984;7:215-21.

6. Lohiya NK, Manivannan B, Mishra PK, Pathak N, Sriram S, Bhande SS, et al. Chloroform extract of Carica papaya seeds induces long-term reversible azoospermia in langur monkey.Asian J Androl 2002;4:17-26.

7. Costa LG, Hodgson E, Lawrence DA, Reed DJ. Current protocol in Toxicology, John Wiley and Sons. Inc; 2005.

8. Tietz NW. Fundamentals of clinical chemistry. Published by WB Saunders Co. West Washington S. G Philadelphia Pa 19105 USA; 1970. p. 173-6.

9. Shahjahan M, Sabitha KE, Malbika J, Shyamala-Devis CS. Effect of Solanum trilobatum against carbon tetrachloride induced hepatic damage in albino rats. Indian $\mathbf{J}$ Med Res 2004;120:194-8.

10. Yakubu MT, Bilbis LS, Lawal M, Akanji MA. Responses of male rat liver and heart aminotransferases to chronic administration of yohimbine. Centrepiont 2005;2:124-31.

11. Nwiloh BI, Nwinuka NM, Monanu MO. The effect of aqueous extract of Carica papaya leaves on liver enzymes and blood cells counts on normal albino rats. Int J Biol Chem Sci 2009;3:561-6.

12. Yakubu MT, Bilbis LS, Lawal M, Akanji MA. Effect of repeated administration of sildenafl citrate on selected enzyme activities of liver and kidney of male albino rats. Nig J Pure Appl Sci 2003;18:1395-4000.

13. Olagunju JA, Oyedapo OO, Onasanya OO, Osoba OO, Adebanjo OO, Eweje O, et al. Effects of isosaline extract of Tetrapleura tetraptera and olax subscopiodes on certain biochemical parameters of albino rats. Pharm Biol 2000;38:187-91. 
14. Akdogan M, Ozguner M, Aydin G, Gokalp O. Investigation of biochemical and histopathological effects of Mentha piperita L. and Mentha spicata L. on liver tissue in rats. Hum Exp Toxicol 2004;23:21-8.

15. Sharma N, Jacob D. Inhibition of fertility and functional alteration in the genital organs of male swiss albino mouse after administration of Calotropis procera flower extract. Pharm Biol 2001;39:403-7.

16. Sarkar M, Gangopadhyay P, Basak B, Chakrabarthy K, Banerji J, Adhikary P, et al. The reversible anti-fertility effect of piper betle Linn. on Swiss albino male mice. Contraception 2000;62:271-4.

17. Sadler TW. Gametogenesis in Langman's medical embryology. 8 ed. Baltimore U. S. A. Willian and Willkins; 2013.

18. Udoh P, Essien I, Udoh F. Effects of Carica papaya (paw paw) seeds extract on the morphology of pituitary-gonadal axis of male Wistar rats. Phytother Res 2005;19:10658.

19. Adebowale AP, Adaikan G, Prasad RNV. Papaya (Carica papaya) consumption is unsafe in pregnancy: fact or fable? Scientific evaluation of a common belief in some parts of Asia using a rat model. Br J Nutr 2002;88:199-203. 